\title{
Long-term safety of biologics in the treatment of psoriasis
}

This article was published in the following Dove Press journal:

Psoriasis: Targets and Therapy

II December 2013

Number of times this article has been viewed

\author{
Manisha R Panchal' \\ Helen Coope ${ }^{2}$ \\ D John McKenna ${ }^{3}$ \\ Anton B Alexandroff ${ }^{3}$ \\ 'Department of Dermatology, \\ Sherwood Forest Hospitals, \\ Kingsmill Hospital, Nottinghamshire, \\ ${ }^{2}$ Novartis Pharmaceuticals UK \\ Ltd, West Sussex, ${ }^{3}$ Department \\ of Dermatology, University Hospitals \\ of Leicester, Leicester Royal Infirmary, \\ Leicester, UK
}

\begin{abstract}
Biologics are novel and important agents in the treatment of severe psoriasis. These agents block specific molecular steps in the inflammatory cascade, thereby reducing activation and proliferation of keratinocytes. Prescreening for biologic agents and careful monitoring of patients is important. There are four biologics currently licensed and used in the treatment of psoriasis in the European Union. This is an evidence-based review examining clinical trials and focusing on the long-term safety data for four biologic agents. Current British Association of Dermatology guidance for the use of biologics in psoriasis and guidelines on the management of psoriasis from the National Institute for Health and Clinical Excellence have been used. Advances on safety information since 2009 in clinical trials are reviewed. The results show that overall there is no statistical significance in the incidence of adverse effects of biologics versus placebo. However, there are serious adverse effects that are reported for biologics that need to be assessed for and addressed promptly. Results of studies discussing major adverse cardiovascular events are also reviewed.
\end{abstract}

Keywords: psoriasis, biologic agents, safety profile, major cardiovascular events

\section{Introduction}

Psoriasis is a chronic inflammatory skin condition that may be associated with joint disease and can have a significant impact on a person's quality of life. There are several forms of psoriasis, with the most common type being chronic plaque psoriasis. This is characterized clinically by well defined red-colored plaques with a silvery scale, corresponding histopathologically to angiogenesis, hyperproliferation, and loss of cell differentiation. Other subtypes include guttate, palmoplantar, flexural, and erythrodermic psoriasis.

Genetic, immunologic, and environmental factors are implicated in the pathogenesis of psoriasis. PSORS-1, a region on the major histocompatibility complex, accounts for up to $50 \%$ of genetic susceptibility to psoriasis. ${ }^{1}$ The presence of an increased number of dendritic cells and T cells in psoriatic plaques demonstrates the functional role of a deregulated immune system in the development of psoriasis.

Biologic therapies used in psoriasis block specific molecular steps of the immunologic pathway that are important in the pathogenesis of psoriasis. Four biologic agents are recommended by the National Institute for Health and Clinical Excellence (NICE) for use in chronic plaque psoriasis, ie, adalimumab, etanercept, and infliximab, which target the cytokine tumor necrosis factor-alpha (TNF $\alpha$ ), and ustekinumab that targets interleukin (IL)-12 and IL-23 (see Figure 1).
Correspondence: Manisha R Pancha Department of Dermatology, Sherwood Forest Hospitals, Kingsmill Hospital, Mansfield Road, Sutton in Ashfield, Nottinghamshire, NGI7 4JL, UK Tel +44 I6 236225 I 5 ext 3198 Email manishamorjaria@hotmail.co.uk 


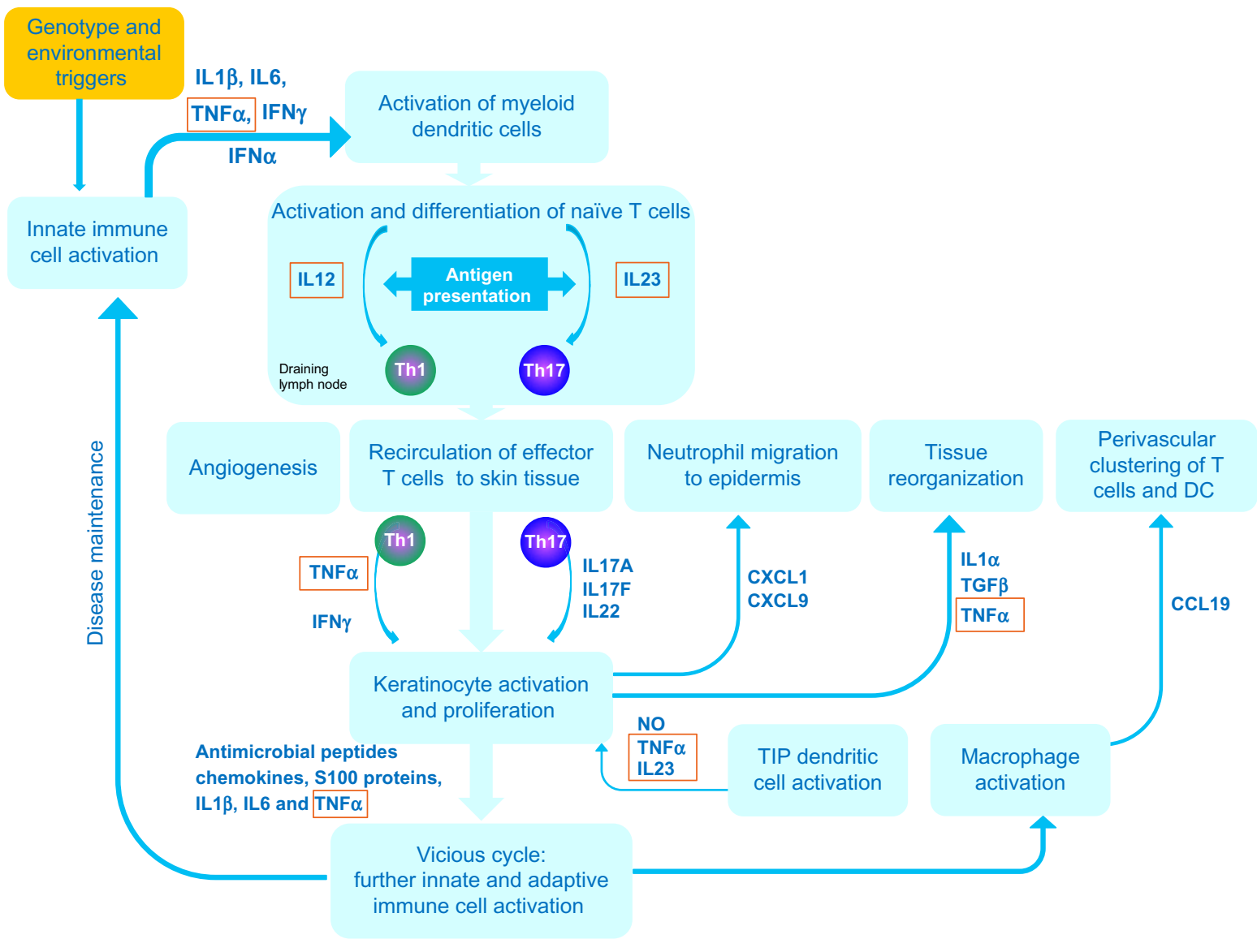

Figure I Mechanism of action of biologic agents.

Notes: Red box indicates cytokine targets of currently marketed biological therapies for the management of psoriasis: ustekinumab targeting the common p40 subunit of ILI 2 and IL23 and etanercept, adalimumab and infliximab targeting TNF $\alpha$.

Abbreviations: TIP, TNF $\alpha$ and inducible nitric oxide synthase producing; DC, dendritic cell; NO, nitric oxide; TNF $\alpha$, tumor necrosis factor-alpha; IFN, interferon; CCL, chemokine (C-C motif) ligand I9; CXCL, chemokine (C-X-C motif) ligand; IL, interleukin; Th, T helper.

Under their respective licenses, adalimumab, etanercept, infliximab, and ustekinumab are all indicated for treatment of moderate to severe plaque psoriasis in adult patients who failed to respond to, who have a contraindication to, or are intolerant of other systemic therapies, including ciclosporin, methotrexate, and psoralen + ultraviolet a (Figure 2). ${ }^{2}$ The British Association of Dermatologists first published guidance on the use of biologics in psoriasis in 2005, and these were updated in 2009. NICE has recently published guidance on the management of psoriasis in 2012. The British Association of Dermatologists Biologic Intervention Register commenced in 2007 and currently has over 140 hospital sites across the UK and Eire recruiting participants for the register. This review assesses the long-term safety of the biologics. A wealth of information about long-term safety will be available on maturity of the data being collected. The longer running British Society for Rheumatology Biologics Registers has been collecting data on the safety of biologics in rheumatoid arthritis since 2001 and in ankylosing spondylitis since 2012 .
However, there are potentially important differences between patients treated with biologics for psoriasis and those treated for other conditions. Patients with psoriasis are known to have an increased risk of cardiovascular disease. ${ }^{3,4}$ They are also likely to have had previous exposure to significant ultraviolet light treatments, which might increase the risk of cutaneous malignancies. ${ }^{5}$ Long-term safety data from the British Society for Rheumatology Biologics Registers may not necessarily apply to those patients treated for psoriasis. This clinical review focuses on the safety profile of biologic agents used for the treatment of psoriasis in the UK. Clinical trials on biologics in the treatment of psoriasis were searched for and analyzed.

\section{Sources and selection criteria}

This is an evidence-based review of the long-term safety of biologic agents in the treatment of psoriasis. We searched the Medline and Embase databases from 2009 to 2012 for clinical trials involving etanercept, adalimumab, ustekinumab, and infliximab. This time frame was selected because the British 


\section{Prescreening for biologics}

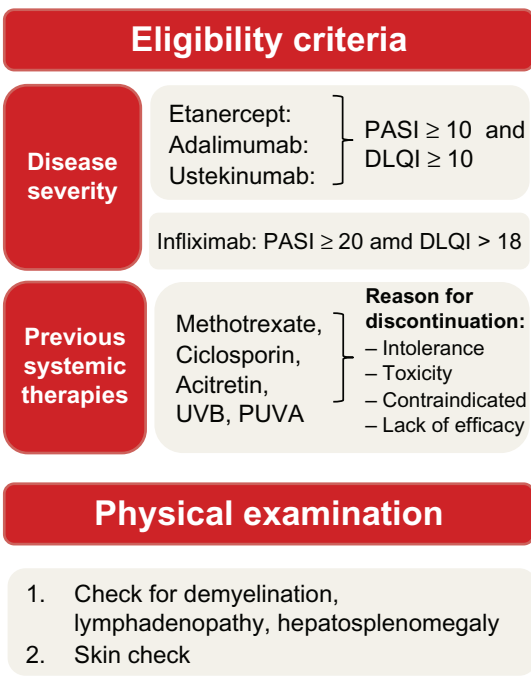

\section{Exclusion criteria}

\begin{tabular}{|c|c|}
\hline $\begin{array}{c}\text { Absolute } \\
\text { exclusion } \\
\text { from } \\
\text { therapy }\end{array}$ & $\begin{array}{ll}\text { 1. } & \text { Pregnancy/breastfeeding } \\
\text { 2. } & \text { Active infection } \\
\text { 3. } & \text { High risk of infection } \\
\text { 4. } & \text { Multiple sclerosis } \\
\text { 5. } & \text { Malignancy (excluding NMSC) }\end{array}$ \\
\hline $\begin{array}{l}\text { Requiring } \\
\text { further } \\
\text { discussion }\end{array}$ & $\begin{array}{l}\text { 1. Previous tuberculosis } \\
\text { 2. Congestive heart failure } \\
\text { 3. Diabetes mellitus } \\
\text { 4. PUVA }>200 \text { especially after ciclosporin } \\
\text { 5. HIV positive } \\
\text { 6. Hepatitis B or C }\end{array}$ \\
\hline
\end{tabular}

\section{Investigations}

1. Chest X-ray

2. Urine dip

3. Bloods: full blood count, urea and electrolytes, liver function tests, fasting lipids, anti-nuclear antibodies, $\mathrm{HIV}$, varicella serology, hepatitis $B$ and $C$, interferon gamma release assay (quantiferon gold/T-spot)

Figure 2 Prescreening for biologic agents.

Note: Screening tool used by the Department of Dermatology at Sherwood Forest Hospitals, Kingsmill Hospital, Nottinghamshire, UK.

Abbreviations: NMSC, nonmelanoma skin cancer; PASI, Psoriasis Area and Severity Index; DLQI, Dermatology Life Quality Index; UV, ultraviolet; PUVA, psoralen + UVA; HIV, Human immunodeficiency virus.

Association of Dermatologists guidelines have reviewed clinical trials prior to 2009. Randomized controlled trials for psoriasis were searched for, because there is an abundance of published data on the disease. We also used NICE guidance published in 2012 and British Association of Dermatologists guidance on the use of biologics in psoriasis as a background for this review. ${ }^{2,6}$

\section{How do biologic agents work?}

Pathogenic mechanisms in psoriasis are complex and involve close interaction between the innate and adaptive immune systems. Although the exact pathology of psoriasis remains poorly understood, it is believed that environmental danger signals activate the innate immune system in genetically predisposed individuals. Such activation of the innate immune system results in production of a number of key cytokines, including IL-1, IL-6, interferon-alpha, and TNF $\alpha$ which, in turn, activate myeloid dendritic cells. The latter activates, differentiates, and propagates antigen-specific $\mathrm{T}$ helper 1 (Th1) and T helper 17 (Th17) $\mathrm{T}$ lymphocyte subsets, so effectively serves as a link between the innate and adaptive immune systems. IL-12 in particular is believed to be crucially important in the production of Th1 cells, while IL-23 plays a similar role in production of Th17 cells (Figure 1). Th1 and Th17 cells both activate and stimulate proliferation of keratinocytes, as well as trigger activation of other elements of the immune response, including neutrophils and macrophages.
Numerous proinflammatory cytokines and chemokines are involved, and the resulting inflammatory response may have a lot in common with other inflammatory responses, such as those observed in lupus and atherosclerosis. ${ }^{4}$ Nevertheless, the intimate details of these pathways remain poorly understood. For example, it is now believed that there is a substantial heterogeneity and plasticity of $\mathrm{T}$ helper subsets. ${ }^{7}$

The biologics, which are currently licensed and used to treat psoriasis in the European Union, act on either TNF $\alpha$ or IL-12/23 pathways. ${ }^{1}$ TNF $\alpha$ inhibitors include infliximab, adalimumab, and etanercept. Infliximab (Remicade ${ }^{\circledR}$, Janssen Biotech Inc, Horsham, PA, USA) is a chimeric mouse-human monoclonal antibody to TNF $\alpha$. Adalimumab (Humira ${ }^{\circledR}$, Abbott Laboratories, North Chicago, IL, USA) is a human monoclonal antibody to TNF $\alpha$. Etanercept $\left(\right.$ Enbrel $^{\circledR},{ }^{\text {Amgen }}$ Inc, Thousand Oaks, CA, USA) is a neutralizing recombinant soluble TNF $\alpha$ receptor (human p75 TNF-receptor Fc fusion protein). Ustekinumab (Stelara ${ }^{\circledR}$, Janssen Biotech Inc), a IL-12/23 inhibitor, is a human monoclonal antibody to the p40 subunit, which is shared by both IL-12 and IL-23 cytokines (IL-12 is made of p19 and p40 subunits while IL-23 is made of p35 and p40 subunits).

\section{Etanercept \\ Guidance so far}

The licensed dose of etanercept for psoriasis is $25 \mathrm{mg}$ twice weekly or $50 \mathrm{mg}$ once weekly. The license further allows use 
of $50 \mathrm{mg}$ twice weekly during the first 12 weeks followed, if necessary, by a dose of $25 \mathrm{mg}$ twice weekly or $50 \mathrm{mg}$ once weekly. However, NICE do not recommend the use of etanercept doses above $25 \mathrm{mg}$ twice weekly or $50 \mathrm{mg}$ once weekly. NICE recommends that treatment should be discontinued in nonresponders at 12 weeks. Nonresponders are classed as patients who fail to achieve a $75 \%$ reduction in their Psoriasis Area and Severity Index (PASI) score from initiation or a failure of 50\% reduction in PASI and a five-point reduction in Dermatology Life Quality Index (Figure 3). ${ }^{8}$

\section{Advances in information regarding safety}

A randomized, double-blind, multicenter Phase III trial with an open-label extension including 618 patients with moderate to severe plaque psoriasis studied the safety and efficacy of etanercept $50 \mathrm{mg}$ twice weekly against placebo and demonstrated that exposure-related rates of adverse events, serious adverse events, infections, and serious infections were similar for placebo and etanercept. ${ }^{9}$

PRESTA was a randomized, double-blind, multicenter trial comparing two etanercept regimens for the treatment of psoriasis and psoriatic arthritis and evaluating an additional 12 weeks of open-label etanercept. This demonstrated no new safety concerns in either treatment group (etanercept $50 \mathrm{mg}$ once or twice weekly) and no significant difference in safety profiles. ${ }^{10}$

The results of a randomized trial comparing ustekinumab and etanercept for moderate to severe plaque psoriasis are discussed in the ustekinumab section of this review. ${ }^{11}$
CRYSTEL evaluated the efficacy and safety of continuous versus paused etanercept in patients over 54 weeks. Patients were randomized to receive continuous etanercept $25 \mathrm{mg}$ twice weekly or paused etanercept $50 \mathrm{mg}$ twice weekly for no more than 12 weeks until reaching a Physicians Global Assessment $\leq 2$. On relapse, etanercept was resumed at $25 \mathrm{mg}$ twice weekly until a Physicians Global Assessment $\leq 2$ was regained. The safety results of this study showed that $7.5 \%$ of patients had a serious adverse event (6.4\% and $8.5 \%$ for the continuous and paused groups, respectively). Four patients, two in each group, had serious infections. There were no cases of tuberculosis or demyelinating diseases observed in this study. ${ }^{12}$

\section{Infliximab}

\section{Guidance so far}

The licensed dose for infliximab is $5 \mathrm{mg} / \mathrm{kg}$, given as an intravenous infusion followed by additional $5 \mathrm{mg} / \mathrm{kg}$ infusions at 2 and 6 weeks after the first infusion, and every 8 weeks thereafter. If a patient shows no response after 14 weeks (ie, after four doses), no additional treatment with infliximab should be given.

However, under NICE guidance, the use of infliximab is restricted to its licensed indication in patients whose disease is very severe (total PASI $\geq 20$ and Dermatology Life Quality Index $\geq 18$ ) and who have failed to respond to standard systemic therapies, such as ciclosporin, methotrexate, or psoralen + ultraviolet $\mathrm{A}$, or the patient is intolerant to or has a contraindication to these treatments. ${ }^{13}$ In addition, under

\section{Impact of NICE guidance on use of biologics}

Evidence based evaluation of efficacy and cost effectiveness
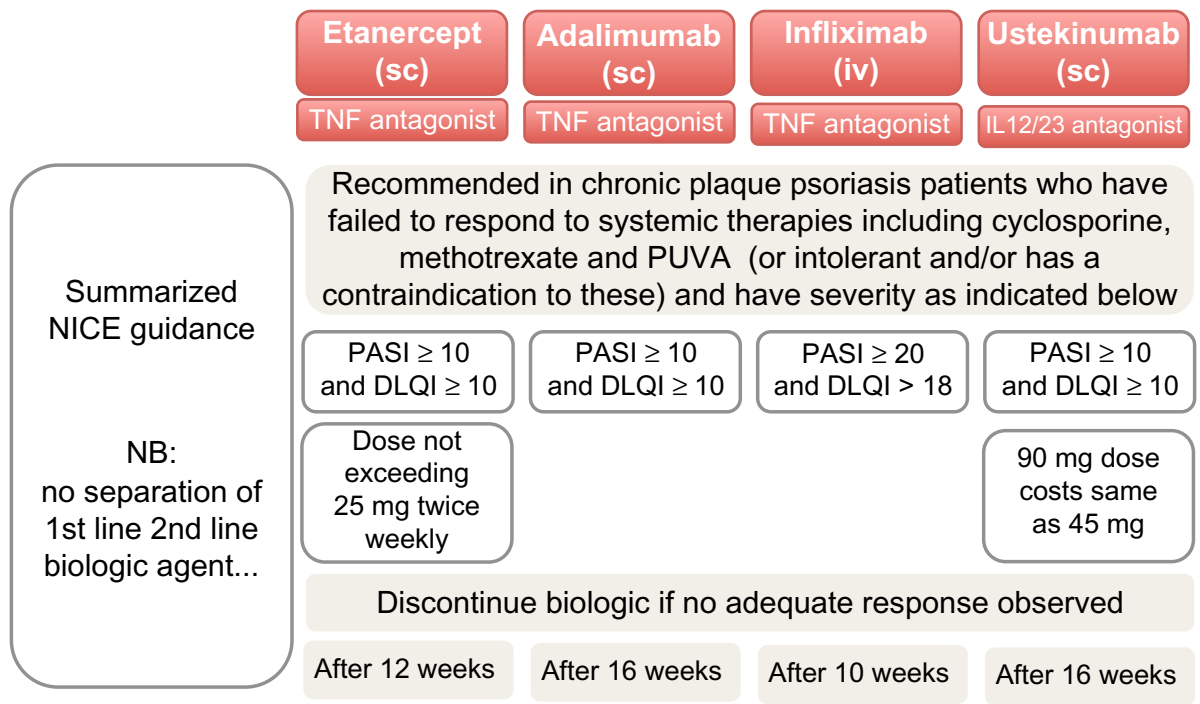

Figure 3 Summary of National Institute for Health and Clinical Excellence evidence on biologic treatments.

Abbreviations: iv, intravenous; sc, subcutaneous; TNF, tumor necrosis factor; IL, interleukin; PASI, Psoriasis Area and Severity Index; DLQI, Dermatology Life Quality Index; NICE, National Institute for Health and Clinical Excellence PUVA, psoralen + UVA; UV, ultraviolet. 
NICE, the efficacy assessment for continuation of treatment is recommended after 10 weeks of therapy (as opposed to 14 weeks in the license, Figure 3$){ }^{13}$

\section{Advances since 2009}

RESTORE 1 was an open-label, randomized, activecontrolled Phase III trial comparing the efficacy and safety of infliximab versus methotrexate. This study demonstrated a similar incidence of overall adverse events in both groups, but the incidence of serious adverse events was slightly higher in the infliximab group. More patients discontinued from the infliximab arm than from the methotrexate arm. Up to week $26,12 \%$ of patients on infliximab and $4 \%$ of patients on methotrexate discontinued due to adverse events. Overall, the study concluded that infliximab was more efficacious than methotrexate and was well tolerated. ${ }^{14}$

\section{Adalimumab Guidance so far}

Under its license, adalimumab is indicated for the treatment of moderate to severe chronic plaque psoriasis in adult patients who failed to respond to, who have a contraindication to, or are intolerant of other systemic therapy, including ciclosporin, methotrexate, and psoralen + ultraviolet A.

The recommended dose of adalimumab for adult patients is initially $80 \mathrm{mg}$ administered subcutaneously, followed by $40 \mathrm{mg}$ subcutaneously given every other week starting one week after the initial dose. Continued therapy beyond 16 weeks should be carefully reconsidered in a patient not responding within this time period (as per the manufacturers instructions).

Under NICE guidance, use of adalimumab is restricted to its licensed indication for patients whose disease is severe (total PASI $\geq 10$ and a Dermatology Life Quality Index $\geq 10$ ) and has failed to respond to standard systemic therapies, such as ciclosporin, methotrexate, or psoralen + ultraviolet A, or the person is intolerant of or has a contraindication to these treatments. The efficacy assessment for continuation of adalimumab is recommended after 16 weeks of treatment (Figure 3). ${ }^{15}$

\section{Advances since 2009}

In 2010, BELIEVE, a randomized, multicenter, doubleblind, vehicle-controlled Phase IIIb study of the efficacy and safety of adalimumab with and without calcipotriol/ betamethasone as topical treatment in patients with moderate to severe psoriasis, demonstrated safety findings similar to those in previous trials conducted with adalimumab. ${ }^{16} \mathrm{~A}$ total of 730 patients were randomized to the study. Thirty-four developed an adverse event leading to discontinuation of the study drug (12/364 [3.3\%] adalimumab + vehicle] and 22/366 $[6.0 \%]$ adalimumab + calcipotriol/betamethasone). The most frequently reported serious adverse event was infection:

- four of $364(1.1 \%)$ on adalimumab + vehicle suffered elective abortion following cytomegalovirus infection, bronchopneumonia, erysipelas, or staphylococcal infection

- six of $366(1.6 \%)$ on adalimumab + calcipotriol/betamethasone developed pneumonia $(n=2)$, erysipelas, herpes zoster, localized infection, or osteomyelitis.

Two cases of malignancy and one case of lymphoma were not thought to be related to the study medication. ${ }^{16}$

A benefit-risk analysis performed on the CHAMPION trial comparing adverse event-free response days in terms of rate of achieving a clinical response without adverse events demonstrated that treatment with adalimumab was associated with significantly more days of adverse event-free response compared with methotrexate or placebo $(P<0.001$ for adalimumab versus methotrexate or placebo). ${ }^{17}$

Safety analysis of adalimumab across subgroups of patients in REVEAL, a randomized, double-blind, placebocontrolled Phase III evaluation of adalimumab every other week in moderate to severe psoriasis, demonstrated no significant differences in risk of serious adverse events in adalimumab-treated versus placebo-treated patients regardless of weight category or baseline comorbidity. ${ }^{18}$

\section{Ustekinumab Guidance so far}

Ustekinumab is recommended as a possible treatment for severe plaque psoriasis affecting quality of life, if the patient's psoriasis has not improved with other treatments, including systemic agents and phototherapy, or if the patient has previously experienced side effects or has specific contraindications as a result of other treatments that would limit their use. ${ }^{19}$

Dosing is weight-dependent and administered via the subcutaneous route. In patients weighing $>100 \mathrm{~kg}$, the licensed dose is $90 \mathrm{mg}$ at weeks 0 , and 4, and 12, and every 12 weeks thereafter, whereas in patients weighing $<100 \mathrm{~kg}$, the dose is $45 \mathrm{mg}$ at weeks 0,4 , and 12 , and every 12 weeks thereafter. ${ }^{20}$ NICE recommends that treatment be discontinued if monitoring standards show that psoriasis has not clearly improved 16 weeks after initiation; however, the license extends for 28 weeks (Figure 3). ${ }^{19}$ 
Rates, types, serious adverse events, adverse events leading to treatment discontinuation, and laboratory anomalies were generally comparable between patients receiving ustekinumab $45 \mathrm{mg}$ and $90 \mathrm{mg}$ during both the placebocontrolled and randomized withdrawal parts of the PHOENIX 1 trial, (ie, 76-week results from this randomized, doubleblind, placebo-controlled trial). ${ }^{21}$

\section{Advances since 2009}

A randomized, multicenter, crossover, controlled trial ( $\mathrm{n}=903$ ) comparing ustekinumab (one group receiving $45 \mathrm{mg}$ and another group receiving $90 \mathrm{mg}$ at weeks 0 and 4) and high-dose etanercept (50 mg twice weekly) for moderate to severe psoriasis demonstrated superior efficacy of ustekinumab over etanercept for treatment of psoriasis. ${ }^{11}$ The safety analysis is as follows:

- similar proportions of patients in each treatment group had at least one adverse event in the first 12 weeks; similar proportions of patients discontinued treatment because of adverse events in both treatment groups

- the greatest disparity was observed in injection site reactions $(24.8 \%$ of patients on etanercept versus $4.3 \%$ on ustekinumab $45 \mathrm{mg}$ versus $3.7 \%$ on ustekinumab $90 \mathrm{mg}$ ); the reason for this disparity may be the frequency of injections required for etanercept

- through 64 weeks, serious infections were higher in patients receiving $90 \mathrm{mg}$ of ustekinumab than in those who received $45 \mathrm{mg}$ of ustekinumab

- one patient developed breast cancer and another developed an oral neoplasm on $45 \mathrm{mg}$ of ustekinumab; one patient developed chronic lymphocytic leukemia and another developed mycosis fungoides on $90 \mathrm{mg}$ of ustekinumab; one patient developed prostate cancer after taking etanercept and crossing over to $90 \mathrm{mg}$ of ustekinumab

- the majority of skin cancers were basal cell carcinomas.

Pooled data from the randomized Phase II and III trials do not suggest an increased risk of infection or malignancy in patients treated with ustekinumab in comparison with the general population. ${ }^{22}$

A meta-analysis of 22 randomized controlled trials including 10,183 patients, performed to evaluate previous reports of an association between major adverse cardiovascular events and IL-12/23, found that there was no significant difference in major adverse cardiovascular events in the IL-12/23 group compared with placebo. However, the followup was short in the meta-analysis and the study may have been underpowered. ${ }^{23}$

\section{Surveillance for cardiovascular events}

Placebo-controlled trials are critical for evaluation of the safety and efficacy of new therapies, but may not have sufficient patient numbers or be of sufficient duration to identify rare safety signals unequivocally. In addition, specific patient inclusion and exclusion criteria may mean patient cohorts in trials are different from "real world" patients. Ethical considerations around the size and duration of placebo-controlled periods can also limit the amount of comparator adverse event data that can be generated. For this reason meta-analyses, postmarketing surveillance, and registry data are of value in identification of rare adverse events.

The evidence that patients with psoriasis have an increased risk of other serious comorbid conditions such as cardiovascular disease has been a topic of intense research for many years, and several authoritative studies have reported an increased cardiovascular risk in patients with psoriasis. ${ }^{24-26}$ It has been proposed that this phenomenon relates to systemic inflammation associated with psoriatic disease.

More recently, two meta-analyses of the placebocontrolled periods of all the randomized controlled trials of adalimumab, etanercept, infliximab, and ustekinumab in psoriasis have examined whether there is an increased risk of major adverse cardiovascular events (MACE) in patients with psoriasis being treated with biologic therapies. ${ }^{23,27}$

MACE events include myocardial infarction, cerebrovascular accident, and cardiovascular death. Both studies compared the incidence of MACE on active drug with that in the placebo comparator groups. Ryan et al analyzed TNF antagonists and IL-12/23 antagonists, whereas Tzellos et al limited their analysis to IL-12/23 antagonists. ${ }^{23,27}$ Both reports included the IL-12/23 antagonist, briakinumab, in addition to ustekinumab, but briakinumab is no longer being actively developed for psoriasis. ${ }^{28}$

The overall incidence of MACE was low in this metaanalysis. During the placebo-controlled phases of the antiIL-12/23 studies, 10 of 3179 patients receiving anti-IL-12/23 therapies experienced MACE compared with zero events in 1474 patients receiving placebo. In the anti-TNF trials, only one of 3858 patients receiving these agents experienced MACE compared with one of 1812 patients receiving placebo. Ryan et al reported that there was no statistically significant increase in the incidence of MACE in patients treated with TNF antagonists or IL-12/23 antagonists. However, using an alternative statistical methodology, Tzellos et al reported a small but statistically significant increase in MACE in patients taking IL-12/23 inhibitors compared with placebo. 
Both analyses reported several potential confounding factors which could have influenced their findings, and were clear that their analyses may not have been powered to detect small but significant differences in MACE rates, so it is clear that larger studies will be needed in the future to advance our understanding of this topic. Table 1 summarizes adverse events observed with the four biologic agents discussed in this review.

\section{Discussion}

Clinical trials on the approved biologic agents demonstrate good efficacy and safety data for their use in patients with moderate to severe psoriasis. The Biologics Intervention Register will highlight important safety issues for biologic agents over a long time period and will determine their future use.

Infections, opportunistic infections, malignancies, and cardiovascular and neurologic disease are some of the more frequent adverse effects observed when using biologic agents. Pretreatment screening is essential for the safety of the patient commencing on biologic therapy, and monitoring during and after treatment is necessary. Many of the trials mentioned above have compared biologic agents with placebo to evaluate both efficacy and safety. Placebos are not used as treatment in clinical practice, and hence there is an emerging need for head-to-head trials comparing biologic agents with longer follow-up periods.

Postmarketing surveillance allows collection of larger datasets but depends on voluntary reporting, so may underreport. In addition, lack of placebo groups in postmarketing surveillance can create "unknown denominator effects". Lastly, safety registries allow prospective systematic collection of large quantities of "real world" data over prolonged periods, so can provide valuable data on long-term safety and detection of rare adverse events. It is important to note that treatments may not be standardized and may introduce confounding variables, eg, coadministration or dose escalation.

\section{Thoughts for the future}

The use of biologic agents for severe psoriasis has been shown to improve disease outcome and quality of life. The risk of experiencing adverse events exists with any agent that suppresses the immune system, so careful monitoring of patients

Table I Summary of adverse events observed with the four biologic agents

\begin{tabular}{|c|c|c|c|c|}
\hline & Etanercept & Adalimumab & Ustekinumab & Infliximab \\
\hline Infections & $\begin{array}{l}\text { Upper Respiratory } \\
\text { Tract Infection (URTI), } \\
\text { skin and soft tissue infection, } \\
\text { pneumonia, opportunistic } \\
\text { infections - tuberculosis, } \\
\text { fungal, protozoan }\end{array}$ & $\begin{array}{l}\text { URTI, skin and soft tissue } \\
\text { infections, fungal infections, } \\
\text { meningitis opportunistic } \\
\text { infections - coccidioidomycosis, } \\
\text { histoplasmosis and mycobacterium } \\
\text { avium complex infection, } \\
\text { tuberculosis }\end{array}$ & $\begin{array}{l}\text { URTI, Nasopharyngitis, } \\
\text { Cellulitis, Diverticulitis, } \\
\text { Osteomyelitis, } \\
\text { Gastroenteritis, } \\
\text { Viral infection, } \\
\text { Urinary tract infection }\end{array}$ & $\begin{array}{l}\text { Viral, Bacterial, } \\
\text { Opportunistic } \\
\text { infections - } \\
\text { pneumocytosis, } \\
\text { candiasis, listeriosis, } \\
\text { aspergillosis and } \\
\text { tuberculosis }\end{array}$ \\
\hline Tuberculosis (TB) & \multicolumn{4}{|c|}{ Evaluate (history and examination) and screen for TB. Not for treatment if active TB or untreated latent TB } \\
\hline Hepatitis B virus & \multicolumn{4}{|c|}{ Can reactivate therefore test prior to initiation and get specialist advise if positive } \\
\hline Allergic reactions & Angioedema, urticaria & Anaphylaxis & $\begin{array}{l}\text { Hypersensitivity, } \\
\text { Severe angioedema }\end{array}$ & $\begin{array}{l}\text { Anaphylaxis, Delayed } \\
\text { hypersensitivity reaction }\end{array}$ \\
\hline Malignancy & $\begin{array}{l}\text { Lymphoma, Leukemia, } \\
\text { Melanoma and NMSC }\end{array}$ & $\begin{array}{l}\text { Non melanoma skin cancer } \\
\text { (NMSC), Lymphoma }\end{array}$ & $\begin{array}{l}\text { NMSC, Prostate, Colorectal, } \\
\text { Breast, Melanoma in-situ }\end{array}$ & $\begin{array}{l}\text { Lymphoma, Leukemia, } \\
\text { Melanoma }\end{array}$ \\
\hline Neurological & $\begin{array}{l}\text { Central and peripheral } \\
\text { demyelination }\end{array}$ & $\begin{array}{l}\text { Central and peripheral } \\
\text { demyelination }\end{array}$ & $\begin{array}{l}\text { Dizziness, Headache, } \\
\text { Facial palsy }\end{array}$ & $\begin{array}{l}\text { Headache, vertigo } \\
\text { dizziness, demyelinating } \\
\text { disorders }\end{array}$ \\
\hline Cardiac & Worsen cardiac failure & Worsen cardiac failure & - & $\begin{array}{l}\text { Tachycardia, Cardiac } \\
\text { Failure, Myocardial } \\
\text { infarction }\end{array}$ \\
\hline Gastrointestinal & Autoimmune hepatitis & $\begin{array}{l}\text { Abdominal pain, nausea, } \\
\text { vomiting }\end{array}$ & Diarrhea & $\begin{array}{l}\text { Diarrhea, uncommon - } \\
\text { intestinal stenosis } \\
\text { and perforation, } \\
\text { pancreatitis, Liver failure }\end{array}$ \\
\hline Vaccinations & \multicolumn{4}{|c|}{ Live viral or bacterial vaccines not to be given } \\
\hline Other & Injection site reactions & Lupus like syndrome & Injection site reactions & $\begin{array}{l}\text { Antinuclear antibodies, } \\
\text { Mood changes, } \\
\text { Interstitial lung disease }\end{array}$ \\
\hline
\end{tabular}


before, during, and after use of such agents is important to ensure patient safety. Using biologics to target specific pathways in the immune system for disease control has been very useful in understanding the pathophysiology of psoriasis.

Achieving better disease control in patients with psoriasis in the future is dependent on both improving patients understanding of the condition and developing newer agents that are more specific. There are three anti-IL-17 drugs now that are proving to be remarkably effective in Phase III trials. These include brodalumab, ixekizumab, and secukinumab. Patients treated in Phase II studies with anti-IL-17 agents showed significant improvement in their psoriasis. ${ }^{29-31}$

In addition to new biologic agents, there are also a number of "small molecule" oral agents in Phase III trials for psoriasis, eg, tofacitinib, which acts intracellularly to inhibit Janus-activated kinase enzymes which act downstream of a number of key cytokines. Apremilast also acts intracellularly to inhibit the phosphodiesterase 4 enzyme, activity of which is required for synthesis of a number of cytokines. Both of these agents have efficacy and safety data supportive of further clinical development, and could offer valuable alternative oral therapies for psoriasis.

In a Phase II trial, Papp et al identified that $67 \%$ of patients achieved a PASI of $75 \%$ using tofacitinib. This agent does not have the same safety issues as the other biologic agents. ${ }^{32}$ There are promising developments in therapies for psoriasis, but it is vital to have long-term safety information because severe side effects can take years to come to the surface.

\section{Conclusion}

Biologic agents are an important treatment option for patients with moderate to severe psoriasis. Achieving good control of psoriasis in an individual has been shown to improve their overall quality of life. It is of prime importance whilst selecting any treatment to keep the patient at the center of care. Identifying patient preferences, such as mode of administration and access, can help increase concordance with therapy.

\section{Acknowledgments}

We acknowledge Ann Launders-Wheatley (dermatology specialist nurse at Sherwood Forest Hospitals), who devised a tool for screening patients prior to initiation of biologic agents referred to in this paper.

\section{Disclosure}

ABA is the Lead for the Comprehensive Local Research Networks Dermatology Specialty Group, a member of the Biologics for Psoriasis Industry Subgroup, and the Steering
Group of the UK Dermatology Clinicall Trial Network; he has received fellowships, plus educational grants, consultancy fees, and acted as an investigator or a member of an advisory board or a director for Abbott Laboratories, Novartis, Pfizer, Procter and Gamble, Merck Serono, Leo Pharma, Basilea Pharmaceutica, Apodi, Genus Pharmaceuticals, GlaxoSmithKline, Medefield, EMS Research, CSD Health Research, XBioCell, Bryter Research, Genactis, Medicus, The Research House, All Global, Keyquest, Teva, Almirall, and Galderma. JM is the Deputy Lead of the Comprehensive Local Research Networks Dermatology Specialty Group, and has received educational grants, consultancy fees, or acted as an investigator for Novartis, Galderma, Abbott, Leo Pharma, Genus Pharmaceuticals, and Almirall. HC is an employee of Novartis.

The authors report no other conflicts of interest in this work.

\section{References}

1. Nestle FO, Kaplan DH, Barker J. Mechanisms of disease psoriasis. N Engl J Med. 2009;361:496-509.

2. National Institute for Health and Clinical Excellence. Psoriasis: full guideline. Available from: http://www.nice.org.uk/guidance/index. jsp?action=download\&o=59182. Accessed April 12, 2013.

3. Pietrzak A, Bartosińska J, Chodorowska G, Szepietowski JC, Paluszkiewicz P, Schwartz RA. Cardiovascular aspects of psoriasis: an updated review. Int J Dermatol. 2013;52:153-162.

4. Alexandroff AB, Pauriah M, Camp RD, Lang CC, Struthers AD, Armstrong DJ. More than skin deep: atherosclerosis as a systemic manifestation of psoriasis. Br J Dermatol. 2009;161:1-7.

5. Archier E, Devaux S, Castela E, et al. Carcinogenic risks of psoralen UV-A therapy and narrowband UV-B therapy in chronic plaque psoriasis: a systematic literature review. J Eur Acad Dermatol Venereol. 2012;26 Suppl 3:22-31.

6. British Association of Dermatologists. British Association of Dermatologists' guidelines for biologic interventions for psoriasis; 2009. Available from: http://www.bad.org.uk/Portals/_Bad/Guidelines/ Clinical\%20Guidelines/Biologics\%20guidelines\%202009.pdf. Accessed April 12, 2013.

7. Zhu J, Paul WE. Heterogeneity and plasticity of Thelper cells. Cell Res. 2010;20:4-12.

8. National Institute for Health and Clinical Excellence. Etanercept and efalizumab for the treatment of adults with psoriasis; 2006. Available from: http://www.nice.org.uk/nicemedia/live/11580/33376/33376.pdf. Accessed April 12, 2013.

9. Tyring S, Gordon KB, Poulin Y, et al. Long term safety and efficacy of $50 \mathrm{mg}$ of etanercept twice weekly in patients with psoriasis. Arch Dermatol. 2007;143:719-726.

10. Sterry W, Ortonne JP, Kirkham B, et al. Comparison of two etanercept regimes for treatment of psoriasis and psoriatic arthritis: PRESTA randomised double blind multicentre trial. BMJ. 2010;340:c147.

11. Griffiths CEM, Strober BE, Van De Kerkhof P. Comparison of ustekinumab and etanercept for moderate-to-severe psoriasis. $N$ Engl J Med. 2010;362:118-128.

12. Ortonne JP, Griffiths CEM, Dauden, et al. Efficacy and safety of continuous versus paused etanercept treatment in patients with moderate-to-severe psoriasis over 54 weeks: the CRYSTEL study. Exp Rev Dermatol. 2008;3:657-665.

13. National Institute for Health and Clinical Excellence. Psoriasis infliximab for the treatment of psoriasis. Available from: http://www. nice.org.uk/ta134. Accessed April 12, 2013. 
14. Barker J, Hoffmann M, Wozel G, et al. Efficacy and safety of infliximab vs methotrexate in patients with moderate to severe psoriasis: results of an open-label, active-controlled randomized trial (RESTORE 1). Br J Dermatol. 2011;165:1109-1117.

15. National Institute for Health and Clinical Excellence. Psoriasis adalimumab technology. Appraisal 146. Available from: http://www. nice.org.uk/ta146. Accessed April 12, 2013.

16. Thaci D, Ortonne JP, Chimenti S, et al. A phase IIIb, multicentre, randomized, double-blind, vehicle-controlled study of the efficacy and safety of adalimumab with and without calcipotriol/betamethasone topical treatment in patients with moderate to severe psoriasis: the BELIEVE study. Br J Dermatol. 2010;163:402-411.

17. Reich K, Signorovitch J, Ramakrishnan K, et al. Benefit-risk analysis of adalimumab versus methotrexate and placebo in the treatment of moderate to severe psoriasis: comparison of adverse event-free response days in the CHAMPION trial. J Am Acad Dermatol. 2010;63:1011-1018.

18. Menter A, Gordon KB, Leonardi CL, Gu Y, Goldblum OM. Efficacy and safety of adalimumab across subgroups of patients with moderate to severe psoriasis. J Am Acad Dermatol. 2010;63:448-456

19. National Institute for Health and Clinical Excellence. Psoriasis ustekinumab technology. Appraisal 180. Available from: http://www. nice.org.uk/nicemedia/live/12235/45461/45461.pdf. Accessed April 12, 2013.

20. Medicines Compendium UK. Ustekinumab Standard of Product Characteristics. Available from: http://www.medicines.org.uk/EMC/ medicine/23207/SPC/Stelara+45+mg+solution+for+injection+in+pr e-filled+syringe/. Accessed April 12, 2013.

21. Leonardi CL, Kimball AB, Papp KA, et al. Efficacy and safety of ustekinumab, a human interleukin-12/23 monoclonal antibody, in patients with psoriasis: 76-week results from a randomised, double blind, placebo-controlled trial (PHOENIX 1). Lancet. 2008;371:1665-1674.

22. Reich K, Papp KA, Griffiths CE, et al. An update on the long-term safety experience of ustekinumab: results from the psoriasis clinical development program with up to four years of follow-up. J Drugs Dermatol. 2012;11:300-312.

23. Ryan C, Leonardi CL, Krueger JG, et al. Association between biologic therapies for chronic plaque psoriasis and cardiovascular events: a meta-analysis of randomized controlled trials. JAMA. 2011;306: $864-871$
24. Gelfand JM, Neimann AL, Shin DB, Wang X, Margolis DJ, Troxel AB. Risk of myocardial infarction in patients with psoriasis. JAMA. 2006;296:1735-1741.

25. Neimann AL, Shin DB, Wang X, Margolis DJ, Troxel AB, Gelfand JM. Prevalence of cardiovascular risk factors in patients with psoriasis. $\mathrm{JAm}$ Acad Dermatol. 2006;55:829-835.

26. Menter A, Griffiths CE, Tebbey PW, Horn EJ, Sterry W; International Psoriasis Council. Exploring the association between cardiovascular and other disease related risk factors in the psoriasis population: the need for increased understanding across the medical community. J Eur Acad Dermatol Venereol. 2010;24:1371-1377.

27. Tzellos T, Kyrgidis A, Zouboulis C. Re-evaluation of the risk for major adverse cardiovascular events in patients treated with anti-IL12/23 biological agents for chronic plaque psoriasis: a meta-analysis of randomized controlled trial. J Eur Acad Dermatol Venereol. March 8, 2012. [Epub ahead of print.]

28. European Medicines Agency. Abbott Laboratories Limited withdraws its marketing authorisation application for Ozespa (briakinumab). Press release, January 17, 2011. Available from: http://www.ema.europa.eu/ docs/en_GB/document_library/Press_release/2011/01/WC500100769. pdf. Accessed April 12, 2013.

29. Papp KA, Leonardi C, Menter A, et al. Brodalumab, an antiinterleukin-17 receptor antibody for psoriasis. N Engl J Med. 2012;336: 1181-1189.

30. Leonardi C, Matheson R, Zachariae C, et al. Anti-interleukin-17 monoclonal antibody ixekizumab in chronic plaque psoriasis. $N \mathrm{Engl}$ J Med. 2012;336:1190-1199.

31. Rich P, Sigurgeirsson B, Thaci DP, et al. Secukinumab induction and maintenance therapy in moderate-to-severe plaque psoriasis: a randomised, double-blind, placebo-controlled, phase II regimenfinding study. Br J Dermatol. September 29, 2013. [Epub ahead of print.]

32. Papp KA, Menter A, Strober B, et al. Efficacy and safety of tofacitinib, an oral Janus kinase inhibitor, in the treatment of psoriasis: a phase $2 b$ randomized placebo-controlled dose-ranging study. $\mathrm{Br} J$ Dermatol. 2012;167:668-677.
Psoriasis: Targets and Therapy

\section{Publish your work in this journal}

Psoriasis: Targets and Therapy is international, peer-reviewed, open access journal focusing on psoriasis, nail psoriasis, psoriatic arthritis and related conditions, identification of therapeutic targets and the optimal use of integrated treatment interventions to achieve improved outcomes and quality of life. The manuscript management system

\section{Dovepress}

is completely online and includes a very quick and fair peer-review system. Visit http://www.dovepress.com/testimonials.php to read real quotes from published authors. 